\title{
ATOS DE LER E BRINCAR NA UNIVERSIDADE: UMA EXPERIÊNCIA DE FORMAÇÃO DE CRIANÇAS, PROFESSORES E ACADÊMICOS
}

\author{
ACTOS DE LEER Y JUGAR EN LA UNIVERSIDAD: UNA EXPERIENCIA DE \\ FORMACIÓN DE NIÑOS, PROFESORES Y ALUMNOS
}

\author{
READING AND PLAYING IN UNIVERSITY: AN EXPERIENCE OF CHILDREN, \\ TEACHERS AND STUDENTS' FORMATION
}

\author{
Aliandra Cristina Mesomo LIRA ${ }^{1}$ \\ Marcos GEHRKE ${ }^{2}$
}

\begin{abstract}
RESUMO: Trata sobre os atos de ler e brincar na universidade, uma experiência de formação de crianças, professores e acadêmicos do curso de Pedagogia, decorrentes de um projeto de extensão desenvolvido entre 2017 e 2018 no contexto de uma universidade pública. Destaca que as ações tiveram como foco a leitura, a brincadeira e a contação de histórias e, foram desenvolvidas por um grupo de bolsistas e voluntários vinculados ao curso de Pedagogia, bem como as crianças e professores da rede pública de ensino e filhos de funcionários da instituição. Problematiza a importância da organização de espaços de leitura e de brincar no contexto universitário, cujas práticas enriquecem a formação dos futuros profissionais e ampliam significativamente o desenvolvimento, aprendizagem, interesse e criatividade das crianças. Considera a parceria entre a universidade e a rede pública de educação como uma estratégia política e pedagógica de formação de todos os sujeitos envolvidos.
\end{abstract}

PALAVRAS-CHAVE: Ler. Brincar. Formação. Extensão.

RESUMEN: Este trabajo trata sobre los actos de leer y jugar en la universidad, una experiencia de formación de niños, profesores y alumnos del curso de Pedagogía, fruto de un proyecto de extensión desarrollado entre 2017 y 2018 dentro del contexto de una universidad pública. Destaca que las acciones tuvieron como foco la lectura, juegos y el cuento de historias, y fueron desarrolladas por un grupo de alumnos becados y voluntarios vinculados al curso de Pedagogía, además de niños y profesores de la red pública de enseñanza e hijos de funcionarios de la institución. Problematiza la importancia de la organización de espacios de lectura y de juegos dentro del contexto universitario, cuyas prácticas enriquecen a la formación de los futuros profesionales y amplían significativamente el desarrollo, aprendizaje, interés y creatividad de los niños. Considera la asociación entre la universidad y la red pública de educación como una estrategia política y pedagógica de formación de todos los sujetos envueltos.

\footnotetext{
${ }^{1}$ Universidade Estadual do Centro-Oeste (UNICENTRO), Guarapuava - PR - Brasil. Docente do Departamento de Pedagogia e do Programa de Pós-Graduação em Educação. Doutora em Educação pela Universidade de São Paulo/USP. ORCID: <https://orcid.org/0000-0003-2945-464X>. E-mail: aliandralira@ gmail.com ${ }^{2}$ Universidade Estadual do Centro-Oeste (UNICENTRO), Guarapuava - PR - Brasil. Docente do Departamento de Pedagogia e do Programa de Pós-Graduação em Educação. Doutor em Educação pela Universidade Federal do Paraná/UFPR. ORCID <https://orcid.org/0000-0002-7592-3139>. E-mail: marcosgehrke@gmail.com
} 
PALABRAS CLAVE: Leer. Jugar. Formación. Extensión.

ABSTRACT: It is about reading and playing in university, an experience of children, teachers and students' formation from Pedagogy course and a project of extension developed between 2017 and 2018 in a public university. It points out the focus of the actions was reading, play and storytelling developed by a group of volunteers and students with scholarship from Pedagogy course, as well as children and teachers from public school and employees' children of the university. It questions the importance of the organization of spaces of reading and playing in the university which ones enrich future professionals' formation and increase especially children's development, apprenticeship, interest and creativity. It considers the association between university and public schools is a politic and pedagogical strategy for everybody's formation.

KEYWORDS: Reading. Playing. Formation. Extension.

\section{Introdução}

A relevância da leitura, das histórias e do brincar na infância tem sido destacada por vasta literatura na área da educação, a qual reforça a importância de ações nesse sentido para formação humana e desenvolvimento das crianças. Além das questões lúdicas envolvidas, as pesquisas ressaltam que vivenciar experiências de incentivo à leitura e de brincadeira contribui para o pleno desenvolvimento infantil. No contexto escolar, muitas vezes, o direito ao brincar e o contato com a literatura é sonegado em nome de práticas centradas em ambientes internos, com crianças sentadas em cadeiras e realizando atividades no papel em carteiras, com privilégio para o ensino de letras e números desde as primeiras experiências institucionalizadas. Considerando esse cenário, foi pensado o projeto, como estratégia para colocar em prática ações de extensão nesses dois eixos.

Nesse sentido, o objetivo desse artigo é apresentar reflexões a partir das experiências vividas no projeto de extensão "Brincar, ler e contar histórias: crianças e professores ocupando a universidade", desenvolvido no contexto de uma instituição pública de ensino superior no período de abril de 2017 a março de 2018, com financiamento da Fundação Araucária. As ações tiveram como foco a leitura, a brincadeira e a contação de histórias desenvolvidas pelos bolsistas e voluntários com crianças e professores da rede pública de ensino e filhos de funcionários da instituição. Metodologicamente, adotamos como estratégia de coleta de dados os registros em diário de campo desses momentos vivenciados, as falas e expressões das crianças, bem como os relatos dos bolsistas. 
Para o texto que segue, no primeiro tópico apresentamos o projeto, seus objetivos e modos de operacionalização. Em seguida, refletimos sobre o brincar no contexto da brinquedoteca, suas possiblidades e contribuições, apresentamos a organização desse espaço no projeto e problematizamos as situações vividas. Num terceiro momento, tratamos da leitura e suas potencialidades, compartilhando as experiências na partilhadas na sala de leitura.

\section{O projeto, seus objetivos e organização}

O projeto de extensão "Brincar, ler e contar histórias: crianças e professores ocupando a universidade" foi desenvolvido entre abril de 2017 e março de 2018, com financiamento de agência de fomento para bolsas, custeio e compra de materiais. As ações do projeto foram desenvolvidas no contexto do Laboratório de Educação Infantil vinculado ao curso de Pedagogia de uma instituição de ensino superior, que existe desde 2012 e está organizado em dois espaços, sala de leitura e brinquedoteca. A equipe executora do projeto contou com dois professores coordenadores, um bolsista recém-formado, graduado em Pedagogia, e 4 bolsistas graduandos de Pedagogia. Ao longo do desenvolvimento do projeto também contamos com grande participação de alunos voluntários, tanto no atendimento às crianças como na confecção de materiais.

O objetivo geral do projeto foi desenvolver práticas formativas com o brincar, ler e contar/ouvir histórias, na articulação adulto e criança no contexto do laboratório. Como objetivos específicos buscou propiciar atendimento às crianças e professores na brinquedoteca, com momentos de brincar; desenvolver a formação de crianças leitoras; promover a circulação de materiais de leitura entre as instituições educativas, por meio das malas itinerantes; organizar e ofertar cursos e oficinas a estudantes e profissionais da área nas temáticas do brincar, ler e contar histórias; selecionar histórias infantis e confeccionar materiais para contá-las. Vale registrar que embora o projeto tenha sido desenvolvido no Laboratório de Educação Infantil a faixa etária das crianças atendidas variou de 1 a 12 anos de idade, pela demanda das instituições atendidas.

Metodologicamente a equipe organizava ações regularmente em reuniões e atendia crianças de escolas com visitas pré-agendadas, além de organizar os espaços de leitura e brincadeira e construir materiais. A seguir indicamos as atividades desenvolvidas: reuniões de planejamento com elaboração de material de divulgação e organização de ações; atendimento às crianças (escolas e filhos de funcionários da universidade) na sala de leitura e brinquedoteca; construção de brinquedos (bilboquê, papa-moscas, vai e vem, pé de lata, varetas gigantes, 
bonecos de pano, etc.), mobiliário para a casinha da brinquedoteca e outros brinquedos (geladeira, fogão, pia, micro-ondas, armário, cabide de fantasias, paleta de aquarela); elaboração de recursos de leitura (pizzas de leitura, cubos de rimas, malas itinerantes, TV de leitura, material ampliado, etc.); oficina para professores sobre a temática da leitura e contação de histórias; empréstimo de materiais de leitura para as instituições e acadêmicos; livro-livre (empréstimo/doação de livros nos corredores da universidade).

Com verba disponível para aquisição de materiais e equipamentos, foi comprado um grande lote de brinquedos diversos e havia a intenção de adquirir um lote de livros de literatura, o que não foi concretizado até a finalização do projeto. Vale registrar que o Laboratório já contava com acervo de brinquedos e livros, o que facilitou o desenvolvimento das ações previstas. Quando os atendimentos eram de turmas de crianças vindas de instituições de ensino organizávamos as mesmas em dois grupos, que se revezavam nos espaços.

Como pontos positivos decorrentes do projeto destacamos: engajamento da equipe executora com total dedicação às atividades do projeto, incidindo positivamente sobre sua formação; interesse e motivação das crianças e professores das escolas em vir à universidade, com fascínio em ocupar esses espaços; grande envolvimento dos acadêmicos participando como voluntários, na confecção de materiais, no atendimento às crianças, no empréstimo dos materiais e uso dos espaços; participação da comunidade em geral nas campanhas de doação de livros e brinquedos; atividades de pesquisa e produção de materiais para a sala de leitura e brinquedoteca; todos os integrantes bolsistas do projeto e também alguns voluntários apresentaram trabalhos científicos (resumos expandidos) em eventos, divulgando o projeto e discutindo os principais resultados decorrentes da experiência; formação de professores de escolas da cidade e região que participaram de visitas e curso organizados pela equipe; produção de material didático inovador, dentre outros.

Dentre as dificuldades enfrentadas tivemos a falta de transporte das crianças até a universidade, provocando cancelamentos ou reagendamentos, salas pequenas para a quantidade de crianças, a demora na aquisição de alguns materiais previstos, dentre outras.

Durante o ano de desenvolvimento do projeto foram atendidas mais de 2.600 crianças, de 6 municípios da região, e também filhos de funcionários ou crianças cujos pais eram atendidos pelo Núcleo de Defesa da Infância e da Juventude (NEDIJ) da universidade.

As duas seções que seguem se dedicam a refletir sobre o papel das práticas lúdicas e de leitura na formação humana, explicitando um pouco mais das ações desenvolvidas em cada espaço. 


\title{
O brincar na casa de brinquedos
}

\author{
Chegamos filho, é aqui \\ Prepare-se, aqui você vai descobrir o vale encantado. \\ Vai chegar a caverna misteriosa. \\ Vai conhecer o estranho laboratório do cientista louco. \\ E eu queria lhe dizer uma coisa: \\ - Não esqueça filho, que uma rosa não é uma rosa, \\ Uma rosa é uma manhã, uma mulher, um grande amor. \\ Uma rosa é uma invenção sua. \\ O mundo é uma invenção sua. \\ Você lhe dá sentido, você o faz bonito, \\ Você o cola de coisas \\ O brinquedo, o que é o brinquedo? \\ Duas ou três partes de plástico, de lata, \\ Uma matéria fria, sem alegria, sem história. \\ Mas não é isso, não é filho? \\ Porque você lhe dá vida \\ Você faz ele voar, viajar, \\ Vamos filho, sabe que lugar é esse? \\ É um lugar de sonhos. \\ Uma casa de brinquedos. \\ Vamos entrar? (TOQUINHO)
}

A música-poesia de Toquinho traduz o mundo da imaginação e das descobertas que o brincar pode proporcionar e está estampada na porta da brinquedoteca aqui descrita. Korczak (1981), ao contar sua experiência como criança reflete que as crianças levam uma vida diferente dos adultos e com direitos que lhes são próprios, entre eles o brincar. Naranjo (2013, p. 27) ao apresentar a compreensão das crianças sobre as coisas da vida traz a fala de um menino de 10 anos para o qual a brincadeira "É estar contente e amando". Ficção e realidade, poesia e concretude, gestos, palavras e cenários se misturam nessa aventura que pode ser o brincar para uma criança.

O tempo da corporalidade infantil é o lugar de intensas aprendizagens. É aqui, e não em outra idade, que a criança vai aprendendo a movimentar-se, caminhar, pegar e mexer nas coisas, gostar e desgostar, chorar, rir, correr, pular, cair, ter medo e se maravilhar. Aprendizagens fundantes de um corpo que culturalmente também vai aprendendo a olhar, falar, cantar, ouvir, desenhar, modelar, dançar, pintar, contar, fazer de conta. Vai aprendendo, rápida ou lentamente, a complexidade do agir e emocionar-se na convivência com outros, aprendendo a interpretar e tomar decisões, a imaginar e narrar, a relacionar e valorar. Aprende a tornarse o que é e o que pode vir a ser no fluir da convivência com outros, ao viver intensamente momentos privilegiados de aprendizagens - porque momento de extrema plasticidade - único em seu acontecer: o momento da primeira vez! (RICHTER; SILVA; FARIA, 2017, p. 241). 
Infelizmente, o mundo do trabalho, das guerras, do consumismo e do individualismo não tem oferecido bons elementos ou condições para um brincar de qualidade às nossas crianças. Brougère (1998) nos ajuda a compreender o brincar como uma ação social aprendida, e nesse vivenciar torna-se imbuída de cultura. $\mathrm{O}$ autor reconhece algumas características essenciais dessa ação, como o faz de conta, a possibilidade de inversão de papéis, a repetição (brincar de novo, e de novo, e de novo) e o acordo entre os parceiros. Assim, a brincadeira seria a tradução de esquemas complexos de combinação entre ficção e realidade, variando segundo alguns aspectos como a cultura e o meio em que a criança está inserida, o gênero e a idade. Como prática vivida, se aprende brincar brincando, uma vez que não há transferência de cultura lúdica, a qual é apropriada pelas interações. Logo, cada sujeito constrói sua cultura, sua interpretação dos significados dos brinquedos, mas também precisa dominar e respeitar certas regras para participar dos jogos e brincadeiras.

Dessa forma, a brincadeira se alimenta de elementos externos e de uma interpretação interna, com grande influência do ambiente, das condições materiais. Ainda segundo Brougère (1998, p.5), “As proibições dos pais, dos mestres, o espaço colocado à disposição da escola, na cidade e em casa, vai pesar sobre a experiência lúdica".

Nessa compreensão, pensar e organizar espaços e práticas de brincadeira requer que consideremos as crianças como sujeitos ativos e competentes, bem como os materiais mais interessantes e potencialmente indutores de um brincar com qualidade. Quanto mais interações das crianças entre si e com os objetos, mais enriquecedora será a experiência advinda da ludicidade. Isso pressupõe considerar, como faz Horn (2017, p. 19), que a criança aprende em todos os locais, por meio das interações com seus companheiros e com o espaço, considerando que este "[...] pode ser estimulante ou limitador de aprendizagens, dependendo das estruturas espaciais que estão postas e das linguagens que ali estão representadas".

A sala da brinquedoteca estava organizada em cantos de brincadeiras, a saber: das artes, casinha, fantasias, de construção e carrinhos, de jogos. No teto estavam móbiles com elementos da natureza, lãs e tecidos e ao centro da sala havia um tapete de EVA com almofadas, e bichos de tecido em tamanho grande. Havia também caixas organizadoras com brinquedos para bebês, bem como alguns para brincar no espaço externo como bolas, cordas, bilboquês, pés de lata, vai e vem, varetas gigantes, dentre outros. $\mathrm{O}$ canto das artes dispunha de dois cavaletes, papel e quadro para desenhos e pintura, massinhas, tintas, pincéis, lápis variados, mesa e cadeiras pequenas. Os materiais estavam dispostos em prateleiras feitas com caixas de frutas de madeira reaproveitadas. Também contamos com azulejos na parede do lado de fora da sala onde a crianças, com as paletas de pintura, desenhavam. Para a casinha foi construída dentro da sala 
uma estrutura com tapumes formando as laterais e teto de tecido, e contava com pia de madeira (feita de pallet), micro-ondas, geladeira, máquina de lavar, fogão e prateleiras feitos de papelão, além de outros artefatos de plástico comprados, bem como utensílios e alimentos variados; anexo à casinha, ao lado, estava um minimercado com embalagens vazias de diversos produtos, onde as crianças 'faziam as compras'. No canto das fantasias construímos cabide com canso de PVC para apoiar as fantasias, bem como dispúnhamos de caixas com tecidos, chapéus, bolsas, óculos, ou seja, acessórios variados, os quais as crianças vestiam e faziam suas representações que podiam ser conferidas em espelho afixado na parede. No canto da construção havia variadas peça de encaixe, bem como carrinhos, caminhões, aviõezinhos e outras variadas miniaturas de meios de locomoção. Em uma parede lateral, o espaço contava com estantes que comportavam jogos de memória, dominós, encaixe, quebra-cabeça, em sua maioria de madeira, os quais as crianças poderiam brincar na mesa disponível ou no chão.

Como registra Horn (2017, s/p), “Organizar de modo satisfatório os espaços, oferecendo possibilidades de brincadeiras, movimentos, investigações, produção de teorias provisórias pelas crianças, descentralizando da figura adulta é, sem dúvida, aspecto-chave [...]”, ou seja, é preciso considerar como os espaços serão usados, como as crianças irão interagir e brincar neles, quais relações são possíveis e como o mobiliário e os materiais serão disponibilizados.

Quando as crianças vinham de instituições públicas ficavam na sala com a presença dos professores das escolas e os integrantes do projeto, como forma de promover a participação dos adultos nesses momentos de brincadeira. Quando se tratava de crianças filhas de funcionários ou de pais que estavam no NEDIJ havia interação e proposição das brincadeiras pelos bolsistas e voluntários, por vezes com a participação dos pais quando as crianças eram muito pequenas. Em todos os momentos privilegiava-se a ação autônoma da criança, num percurso carregado de emoções, desafios e diferentes arranjos.

De modo geral avaliamos que os momentos no espaço da brinquedoteca foram extremamente ricos para a construção de vínculos, para o exercício do brincar e a resolução de conflitos decorrentes das brincadeiras, condições que incidem positivamente no desenvolvimento humano como um todo. Do ponto de vista da logística o espaço demonstrouse pequeno em alguns momentos para comportar os grupos de crianças quando vinham de instituições, causando alvoroço, mas nada que tenha impedido as crianças de brincarem sendo que, com frequência, os arranjos do espaço e os materiais passavam por pequenas alterações como forma de atender às necessidades de cada momento. Os cantos preferidos pelas crianças eram o da fantasia e da casinha, sendo pouco utilizados os jogos de mesa, o que concluímos ser por sua semelhança com alguns materiais já disponíveis nas instituições de origem. Nas 
brincadeiras na casinha o mobiliário em tons neutros procurou estimular e chamar a atenção para que meninos e meninas fizessem suas representações nesse espaço, o que aconteceu.

Como entende Horn (2017), o caráter circunscrito dos contextos contempla a reunião em grupos menores, espaços e materiais mais definidos e relações mais complexas, o que propiciará a possibilidade de observações mais aprofundadas dos processos colocados em prática pelas crianças, sustentando intervenções que levem as crianças a construírem novas relações e conhecimentos. Nesse sentido, o professor

[...] com intencionalidade educativa planeja, organiza e coloca à disposição das crianças tempos, espaços e materiais para que favoreçam provocações à imaginação e desafios ao raciocínio, dando asas à curiosidade, proporcionando espanto, descoberta, maravilhamento e todas as formas de expressão nas mais diferentes intensidades (RICHTER; SILVA; FARIA, 2017, p. 246).

Nossa perspectiva de atuação procurou pensar e projetar ações como forma de proporcionar experiências educativas que pudessem ser vividas de forma lúdica pelas crianças. Nesse processo, o protagonismo infantil deu a tônica dos acontecimentos, sendo privilegiada a observação das interações vividas, condição que proporcionou desenvolvimento às crianças e também aos integrantes do projeto, como formadores e futuros profissionais brincantes. $\mathrm{O}$ impacto na formação dos bolsistas e voluntários foi sobremaneira positivo, uma vez que puderam vivenciar concretamente o exercício da docência em ações de brincadeira e leitura, bem como refletir sobre elas a partir da sistematização escrita da experiência vivida e seu compartilhamento.

\section{A leitura na sala do menino que lia o mundo}

E ele conta que, quando chegou a escola e já sabia "ler muitas coisas" do mundo das coisas, das pessoas, da vida e do mundo das palavras, ele aprendeu algo muito importante. Aprendeu que para aprender os "ensinos" da ESCOLA - a "escolinha-de-primeiras-letras" - ele não precisava deixar de aprender as lições do MUNDO e as lições da VIDA (BRANDÂO, 2014, p. 21).

A leitura e os espaços de ler, contar-ouvir histórias são fundamentais quando pretendemos planejar práticas de leitura para crianças, professores e futuros pedagogos e pedagogas, todos leitores em potencial, que não precisam, na escola, deixar de ler o mundo, as coisas, a vida.

O projeto de leitura desenvolvido assumiu, entre tantos autores, especialmente, as concepções de leitura de Paulo Freire para fundamentar e planejar os 'atos de ler' na 'Sala do 
Menino que lia o mundo ${ }^{3}$, nome dado ao espaço criado. Ele recebe as crianças e professoras das escolas públicas, filhos de trabalhadores da instituição, bem como, estudantes da universidade.

Visitar e revisitar autores e suas obras sobre leitura, por meio da leitura, foi a estratégia metodológica. Fundamentar-se, aproximar-se de autores pelo texto, aprender com eles, portanto, ler foi o passo inicial. Revisitamos o clássico Pedagogia do Oprimido (1967), onde a leitura é vinculada ao trabalho de alfabetização e, aprender a ler é compreendido como possibilidade de o adulto dizer sua palavra; a obra A importância do ato de ler: em três artigos que se complementam (1982), demarca a concepção de leitura da palavramundo, e sobre a importância do ato de ler, sempre político e humano. Visitamos Carlos Rodrigues Brandão (2002; 2005; 2014) que, em três obras escreve e reescreve a História do Menino que lia o mundo, o menino Paulo Freire.

Lemos Paulo Freire menino e, como aprendeu a ler a palavra e o mundo em espaços como, seu quintal e o chão das sombras das mangueiras; o Recife, Jaboatão e o nordeste brasileiro; na escola da professora Eunice. Mas alertava.

No esforço de re-tornar a infância distante, a que já me referi, buscando a compreensão do meu ato de ler o mundo particular em que me movia, permitam-me repetir, re-crio, re-vivo, no texto que escrevo, a experiência vivida no momento em que ainda não lia a palavra (FREIRE, 1984, p. 14).

Ainda menino,

[...] fui me tornando íntimo do meu mundo, em que melhor o percebia e o entendia na leitura que dele ia fazendo, os meus temores iam diminuindo. Mas, é importante dizer, a "leitura" do meu mundo, que me foi sempre fundamental, não fez de mim um menino antecipado em homem, um racionalista de calças curtas. A curiosidade do menino não iria distorcer-se pelo simples de ser exercida, no que fui mais ajustado do que desajustado por meus pais (FREIRE 1984, p. 16).

De menino a gente grande, de estudante a professor, Paulo Freire seguiu seu caminho de leitor, que foi lendo cada vez mais e melhor as contradições de classe no seu mundo. Essa leitura sempre moveu Freire no seu 'que fazer' e, com isso experimentou a leitura na universidade, no Movimento de Cultura Popular, na prisão, no exilio e, tantos outros espaços. Paulo Freire (1884, p. 19) escreve:

${ }^{3}$ A sala de leitura recebeu o nome de "História do menino que lia o mundo" (BRANDÃO, 2014), para homenagear Paulo Freire. 
Em minha andarilhagem pelo mundo, não foram poucas às vezes em que jovens estudantes me falaram de sua luta às voltas com extensas bibliografias a ser muito mais "devoradas" do que realmente lidas ou estudadas [...]. A insistência na quantidade de leituras sem o devido adentramento nos textos a ser compreendidos, e não mecanicamente memorizados, revela uma visão mágica da palavra escrita.

Paulo Freire leu o mundo, a palavra e escreveu uma extensa bibliografia. Hoje lemos e estudamos o que ele escreveu sobre ler e escrever. Para Chauí (1994) que leu Paulo Freire, ler é aprender a pensar na esteira deixada pelo pensamento do outro. Ler é retomar a reflexão de outrem como matéria-prima para o trabalho de nossa própria reflexão. Ler implica em identificar os significados conferidos pelo autor a seu texto.

Alfredo Bosi (1988), que também leu Feire diz que a boa colheita de uma leitura está em distinguir e escolher adequadamente os sentidos originalmente propostos na obra. Ele segue dizendo:

\begin{abstract}
A palavra que eu leio (lego: colho) na sua ingrata renitência sobre a página do livro desafia-me como a pergunta da Esfinge: a resposta pode variar ao infinito, mas o enigma é sempre o mesmo: o que eu quero dizer? Ler é colher tudo quanto vem escrito. Mas, interpretar é eleger (ex-leger: escolher), na messe de possibilidades semânticas, apenas aquelas que se movem no encalço da questão crucial: o que o texto quer dizer? (BOSI, 1988, p. 274- 275).
\end{abstract}

Tomando o pensamento de Bosi, poder-se-ia dizer que, para fazermos a interpretação, respeitando aquilo que o autor quis dizer, implica na decifração do enigma do texto. Supõe um leitor com paciência, mentalidade alargada, com capacidade de aprender as diferenças entre cada autor, admirando um texto, sem necessariamente admirar o autor e seu pensamento, admirar o texto no sentido de sua tessitura.

Freire (1984), na importância do ato de ler, traz a mesma reflexão desde seu chão, o quintal com as mangueiras, de onde aprendeu desde menino, ler e compreender. Assim define:

\begin{abstract}
A leitura de mundo precede a leitura da palavra, daí que a posterior leitura desta não possa prescindir da continuidade da leitura daquele. Linguagem e realidade se prendem dinamicamente. A compreensão do texto a ser alcançada por sua leitura crítica implica a percepção das relações entre o texto e o contexto [...] (FREIRE, 1984, p. 11-12).
\end{abstract}

Nesse processo, de idas e vindas, ele continua:

Na proposta a que me referi acima, este movimento do mundo à palavra e da palavra ao mundo está sempre presente. Movimento em que a palavra dita flui do mundo mesmo através da leitura que dele fazemos. De alguma maneira, porém, podemos ir mais longe e dizer que a leitura da palavra não é apenas 
precedida da leitura de mundo, mas por uma certa forma de "escrevê-lo" ou de "reescreve-lo", quer dizer, de transforma-lo através de nossa prática consciente (FREIRE, 1984, p. 19).

As ideias-força ${ }^{4}$ de Freire sobre leitura demarcam a mesma como um processo de interação entre o leitor, o escrevedor, o texto, o contexto, os suportes de leitura, na perspectiva dos propósitos que o primeiro se coloca.

O conjunto da obra analisada permite destacar que a leitura em Freire destaca a presença de um leitor crítico que processa e examina a palavramundo (texto) no círculo de cultura (FREIRE, 1987; 2001), por meio do diálogo (FREIRE, 1987). E, nos processes de ler, o leitor ou os mediadores precisam estabelecer objetivos, propósitos, finalidades, interesses para orientar o ato da leitura. Nessa perspectiva o leitor se forja ledor-escrevedor (GEHRKE, 2010) que, ao se dar conta deste conjunto de relações, aprendeu e descobriu a necessidade de escrever sua palavramundo, seus enunciados e comunicá-los, logo, ler colabora na formação de um sujeito que escreve e permite a formação do acervo da biblioteca (GEHRKE, 2014).

Essas considerações colaboraram na definição do projeto de leitura, que articulou necessariamente: a definição dos sujeitos potenciais leitores, as crianças e professoras das redes municipais de ensino, acadêmica do curso de pedagogia; os propósitos da leitura; a organização do espaço (na sala de leitura); e o acervo. Para, a partir disso, planejar as práticas de ler e ouvircontar histórias.

O leque de objetivos e propósitos definidos no projeto circunstanciaram:

a) o espaço ou a sala de leitura: ser o espaço do círculo de leitura para crianças e professoras; receber material doado da comunidade; agregar diferentes suportes de leitura; local de contar-ouvir histórias; dinamizar o acervo interna e externamente; ser referência de organização do acervo; expor ideias e práticas dos acadêmicos; reunir acadêmicos para ler;

b) seu acervo: ser catalogado formando a biblioteca; agregar diferentes suportes e gêneros discursivos; disponibilizar o acervo para os usuários; fornecer material para os estágios do curso; circular as malas itinerantes;

c) os usuários: ler; ouvir histórias; informar-se; buscar informações; divertir-se; brincar; dialogar no círculo de leitura;

d) os trabalhadores do projeto (bolsistas e voluntários): atender aos usuários; contar histórias; ler para as crianças e professoras; cadastrar o acervo; produzir material didático.

A definição de objetivos e o planejamento com a constante avaliação dos envolvidos, possibilitou a realização de um conjunto de práticas de ler, ouvir-contar histórias. Destacamos, o empréstimo de obras literárias para o conjunto de acadêmicas do curso de pedagogia para leitura e uso nos estágios; a aquisição do acervo desde a compra e o recebimento de doação,

${ }^{4}$ No sentido Freireano.

RIAEE - Revista Ibero-Americana de Estudos em Educação, Araraquara, v. 14, n. 2, p. 620-633, abr./jun., 2019. E-ISSN: 1982-5587. 
totalizando um mil e quinhentas obras, aproximadamente; produção de material didático para o trabalho de ler e contar histórias; circulação de malas itinerantes de leitura nas escolas; realização de dois cursos de contação de história para professores das redes de ensino; participação do projeto em eventos da universidade; atendimento itinerante nas escolas municipais; disponibilização do livro livre como uma prática de aproximar o acervo dos leitores potenciais.

As práticas de ler e contar-ouvir histórias na sala do menino que lia o mundo, fizeram uso do livro como suporte básico nos atos de ler e de contar histórias. Prática complementada ou apoiada com cenários específicos, fantoches, personagens e outros, incluindo também momentos de visitação livre no espaço e acervo para conhecer os livros e ler individualmente.

Como um dos propósitos e estratégias era a formação de leitores, buscamos dialogar com as crianças, especialmente, chamando a atenção para o espaço e acervo, questionado: Suas escolas têm livros e biblioteca? Eles são usados? Podemos organizar a biblioteca na escola? Vocês ajudariam organizar? Acham importante? Que nome ela poderia receber? Questões que pretenderam laçar sementes, no sentido de forjar a biblioteca na escola como direito da criança.

Consideramos que a leitura crítica é condição para a educação libertadora e a ação cultural para liberdade, desafio para as escolas, a universidade, as bibliotecas e a formação de professores, se pretendem formar sujeitos capazes de ler a palavramundo, as coisas da vida, o mundo.

\section{Considerações finais}

A articulação entre universidade, representada pelos professores formadores e acadêmicos, com a comunidade externa, no caso do projeto crianças e professores, constituiuse em experiência colaborativa para todos os envolvidos. Assim, desde a formação do leitor, o contato com a literatura, a vivência do brincar, as situações vividas incidiram positivamente na formação humana dos sujeitos.

Do ponto de vista da criança, a formação do leitor perene, o conhecimento de obras da literatura, o desenvolvimento da imaginação e da capacidade de ouvir e contar histórias contribuíram com o alargamento das visões de mundo e a formação de sujeitos críticos e reflexivos. No contexto de brincadeira, apropriaram-se do mundo pela representação de situações reais, usando a criatividade, ouvindo o outro e resolvendo conflitos, com impactos no desenvolvimento intelectual, social e cultural. 
Quanto aos professores que acompanharam as crianças das escolas, puderam reconhecer possibilidades de organização do espaço e de práticas que envolvam a brincadeira e a leitura, participando de momentos de formação no contexto da universidade, compartilhando dificuldades e repensando modos de ação mais participativos do ponto de vista das crianças.

Para os acadêmicos do curso, bolsistas ou voluntários, a oportunidade de vivenciar, durante sua formação inicial, experiências com grupos variados de crianças, com demanda, dificuldades e modos de participação diversos, exigiu que elaborassem saberes da docência articulados às teorias que estudam. A experiência para além dos muros da sala de aula da universidade, permitiu alargar o olhar a partir das estratégias de ação colocadas em prática e da interação entre adultos e crianças.

Como coordenadores do projeto, identificamos os impactos positivos que as experiências de extensão promovem ao ambiente formador, impulsionando novas pesquisas, diferentes articulações entre universidade e comunidade, diminuindo o distanciamento entre teoria e prática.

\section{REFERÊNCIAS}

BOSI, A. A interpretação da obra literária. In: BOSI, A. Céu, inferno. Ensaios da crítica literária e ideológica. São Paulo: Ática, 1988.

BRANDÃO, C. R. História do menino que lia o mundo. Movimento dos Trabalhadores Rurais Sem Terra. Caderno Fazendo História, n. 7. São Paulo, 2002.

BRANDÃO, C. R. Paulo Freire, o menino que lia o mundo: uma história de pessoas, de letras e palavras. São Paulo, Editora UNESP, 2005.

BRANDÃO, C. R. História do menino que lia o mundo. São Paulo, Expressão Popular, 2014.

BROUGÈre, G. A criança e a cultura lúdica. Rev. Fac. Educ., São Paulo, v. 24, n. 2, p. 103116, 1998. Disponível em: http://www.scielo.br/scielo.php?script=sci_arttext\&pid=S010225551998000200007\&lng=pt\&nrm=iso. Acesso em: 04 abr. 2018.

CHAUÍ, M. Introdução à história da filosofia. Dos pré-socráticos a Aristóteles. São Paulo: Brasiliense, 1994.

FREIRE P. A importância do ato de ler: em três artigos que se completam. São Paulo: 8 ed. Cortez Editora, 1984.

FREIRE, P. Pedagogia do oprimido. Rio de Janeiro: Paz e Terra, 1987.

FREIRE, P. Ação cultural para liberdade e outros escritos. São Paulo, Paz e Terra, 2001. 
GEHRKE, M. Escrever para continuar escrevendo: as práticas de escrita da Escola Itinerante do MST. Dissertação de mestrado em educação, Universidade Federal do Paraná, Curitiba, 2010.

GEHRKE, M. Contribuições da práxis para a constituição da biblioteca escolar do trabalho a partir da Educação do Campo. 2014.Tese (Doutorado em educação) Universidade Federal do Paraná, Curitiba, 2014.

HORN, M. da G. S. Brincar e interagir nos espaços da escola infantil. Porto Alegre: Penso, 2017.

KORCZAK, J. Quando eu voltar a ser criança. São Paulo: Summus, 1981.

NARANJO, J. Casa das estrelas. O universo contado pelas crianças. Rio de Janeiro: Foz, 2013.

RICHTER, S. R. S.; SILVA, A. A. da; FARIA, A. L. G. de. A educação encontra a arte: apontamentos político-pedagógicos sobre direitos e pequena infância. Revista Zero a Seis, Florianópolis, v. 19, n. 36, p. 235-251, jul./dez. 2017.

\section{Como referenciar este artigo}

LIRA, Aliandra Cristina Mesomo; GEHRKE, Marcos. Atos de ler e brincar na universidade: uma experiência de formação de crianças, professores e acadêmicos. Revista IberoAmericana de Estudos em Educação, Araraquara, v. 14, n. 2, p. 620-633, abr./jun., 2019. EISSN: 1982-5587. DOI: 10.21723/riaee.v14i2.11682

Submetido em: $13 / 08 / 2018$

Aprovado em: 25/10/2018 